with the same antigen since our source of material is the same. Hopefully, co-operative and collaborative efforts will accelerate the eventual realization of an effective human vaccine to protect against malaria. The process of achieving this end should not be exacerbated by deliberate or inadverten downgrading or misrepresentation. As a former British resident and university graduate, I have been saddened by the erosion of suppont for research in that country. Hopefully, the erosion will nor also affect the British sense of decency and fair play.-I am, etc.,

University of New Mexico,

U.S.A.

1 Freund, J., et al., Science, 1945, 102, 202.

Freund, J., et al., American fournal of Tropical

Targett. A. T., and Fulton, J. D., Experi Parasitology, 1968, 58, $18 \mathrm{P}$. 1970, 28, 318 . $6 \begin{gathered}\text { Brown, K. N., Brown, I. N., and Hills, L. A. } \\ \text { Experimental Parasitology, 1970, 28. 304. }\end{gathered}$ Mitchell, G. H., Butcher, G. A., and Cohen, A.
Nature, 1974, 252, 311.

D'Antonio, L. E., Dagnillo, D. M., and Silverman, P. H., Federation Proceedings, 1971, 30

Schenkel, R. H., Simpson, G. L.. and Silverman P. H., Bulletin of the World Health Organiza-
tion, 1973, 48, 597 .

, P. H., Nature, 1974. 247, 304

12 Beckwith. R., Schenkel, R. H.. and Silverman, P. H., Experimental Parasitology. In press. In press.

\section{Royal College of Radiologists}

SIR,-I was very pleased to read the welcome given in your leading article (19 April, p. 108) to the Royal College of Radiologists and oompletely endorse the remarks which you make about diagnostic radiology. However, I am sure you are aware that the Faculty of Radiologists, since its inception, and now the Royal College of Radiologists, includes therapeutic as well as diagnostic radiology, and I am sure you will agree that the contributions of radiotherapy in the management of patients with malignan disease, whether as a single form of treatment or as one of a range of oncological treatments, are worthy of note.

The remarks in your article about inadequacy of academic teaching, the dearth of academic departments, and the likelihood of exciting advances in the future apply equally to radiotherapy as to radiodiagnosis. -I am, etc.,

Newcastle upon Tyne

WIILIAM M. Ross

\section{Congenital Defects of the Anterior} Abdominal Wall

SIR,-Your recent leading anticle on this subject (29 March, p. 701) summarizes the problems encountered, but certain points merit further attention.

In a series of 53 consecutive cases which I reported recently ${ }^{1}$ the overall surgical mortality was $47 \%$, but this rose to $66 \%$ Medicine, 1948, 28, 11 Brown, K. N., Brown, I. N., and Trigg, P. I.

Brown, K. N., et al., Experimental Parasitology,

Schenkel, R. H., et al., fournal of Parasitology.

(14 cases) in premature neonates. ${ }^{1}$ The results of the staged repair and the Silastic sac technique in 29 cases of major exomphalos in premature and normal-birthweight neonates are compared in the table. Though the numbers reported are small, the high incidence of respiratory complications contributing to mortality $(57 \%$ of deaths in the first 24 hours in this series) suggest that where surgery is contemplated the Silastic sac deserves greater consideration than your leading article implies.

A notable omission in your article was the mention of infection as a significant cause of mortality; this accounted for eight $(29.5 \%)$ of the deaths out of the total of 27 (two inoperable) in this series and emphasizes the need to avoid contamination in handling the exomphalos.

The transfer of these babies to a specialzed unit is often associated with hypothermia. Rectal temperature on arrival was $35^{\circ} \mathrm{C}$ or less in $42^{\circ} \circ$ of our patients. This figure suggests that there is considerable scope for improvement in methods of temperature conservation when transporting these high-risk cases.-I am, etc.,

\section{Department of Anaesthetics,}

Hallamshire Hospital,

D. W. RYAN

1 Ryan, D. W., Anaesthesia, 1973, 28, 407.

\section{Colour Disturbance as a Symptom}

SIR,--Your most interesting leading article (5 April, p. 2) has focused attention on a change of colour-awareness as an incidental finding in certain ocular, neurological, and systemic disorders. You refer to the fact that xanthopsia (yellow-vision) may be iatrogenic in origin and be induced by such drugs as digitalis, sulphonamides, and phenacetin and also to the development of colour impairment in toxic amblyopia, but you fail to mention the red-green colour defect which is a diagnostic feature of tobacco amblyopia.

You funther state that such a change in colour-awareness is usually so gradual that it is unnaticed by the patient and that even when it is observed, unless it is gross, it is difficult to test without recourse to esoteric instruments. I would remind you that the Oxford English Dictionary defines esoteric as being "designed for, or appropriate to, an inner circle of advanced or privileged disciples," but I am sure that it is not your intent to imply that investigation of visual fields in neuro-ophthalmological disorders should be included in this category and thereby be exalted to mystic status.

The visual field changes in tobacoo amblyopia are very characteristic. ${ }^{2}$ They consist of a centrocaecal scotoma, usually bilateral though not necessary equal on the two sides. The scotoma is horizontally oval, with a sloping edge, and is most easily detected by a reduced stimulus suoh as a red or small white test object. The defect for colour exceeds that for white and there are usually definite nuclei within the scotoma on

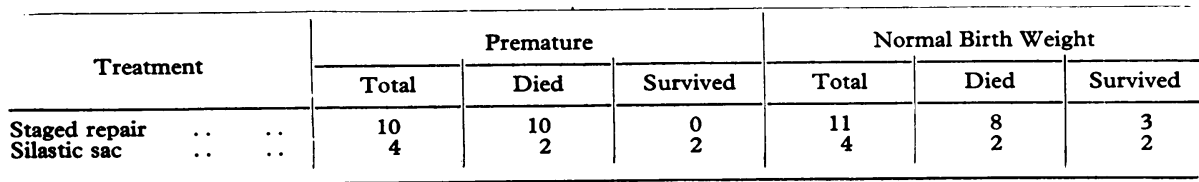

the horizontal meridian. An impairment of the temporal colour field exists within the $30^{\circ}$ circle and, in the more advanced cases, a similar defect is also seen to a small white test object.

I do not accept your contention that this change in colour-awareness is unnoticed by the patient. This has certainly not been the case in many of my patients with tobacco amblyopia. The first symptom is an inability to distinguish between the colours red and green before the vision for white is materially reduced. I recall that one patient with tobacco amblyopia, who was a market gardener, became somewhat disconcerted by the apparent failure of the apples in his orchard to ripen. It was not until a friend of his pointed out that the apples were in fact red and not green that he realized that his appreciation of colour was at fault. Another of our patients was under the impression that it was really his wife who should be seeking medical advice as he had noticed that her cheeks had lost their natural ruddy complexion.

The medicolegal aspect is important in that if a road user or engine driver suffers from tobacco amblyopia it may not be possible for him to distinguish between the green and red traffic lights or railway signals. Shortly after our work on the aetiology of tobacco amblyopia was published this colour disturbance was suocessfully used by defence counsel in a court case involving an engine driver who was a heavy pipe-smoker and who had ignored the red danger signal and caused an accident on the railway.

In connexion with this change in colourawareness it is important to remind ourselves that besides being present in tobacco smoke and alcohol, cyanide has a worldwide distribution in the plant kingdom Cyanide is also liberated from the combustion of vegetable matter and in areas contaminated with untreated sewage. If the indiscriminate dumping of industrial cyanide waste continues unchecked there may well come a time when more widespread chronic cyanide neurotoxicity oocurs from a dietary source in persons with a genetic or acquired error of cyanide or vitamin $\mathrm{B}_{12}$ metabolism. ${ }^{3}$ - I am, etc.,

Princess Margaret Hospital,

\section{A. G. FrEemaN}

Heaton, J. M., McCormick, A. I. A., and Freeman, A. G., Lancet, 1958, 2. 286.
Freeman, A. G., and Heaton, J. M., Lancet, Freeman, A. G.. British Metical fournal, 1973 1, 231 .

\section{Postoperative Management after Thymectomy}

SIR,-We read the letters of Drs. L. Loh and J. M. Newsom Davis and Mr. M. J. Lange and Dr. T. H. Howells (5 April, p. 37) with interest. The former recommend nasotracheal intubation of all patients, the latter only of some. The former reduce anticholinesterases acoording to the response to the edrophonium (Tensilon) test, the latter consider them unnecessary in the immediate postoperative period but recommence drugs after 6-12 hours (para. 7) or after 48 houns (para. 8). This would seem to indicate that no single policy for the management of these patients has yet been generally agreed. We would claim for our paper (8 February, p. 309) only that it is an attempt to bring some 